\title{
Local Government Staff Performance Management in Tanzania: Experience of Open Performance Review and Appraisal System (OPRAS) in Kinondoni Municipal Council
}

\author{
P. Mtasigazya \\ Department of Social Studies, The Mwalimu Nyerere Memorial Academy- Karume Campus, \\ P. O. Box 307, Zanzibar, Tanzania
}

For citation: Mtasigazya P. Local Government Staff Performance Management in Tanzania: Experience of Open Performance Review and Appraisal System (OPRAS) in Kinondoni Municipal Council. Vestnik of Saint Petersburg University. Asian and African Studies, 2021, vol. 13, issue 1, pp. 51-73. https://doi.org/10.21638/spbu13.2021.104

The article presents a study that examined the effectiveness of the implementation of OPRAS on local government staff performance in the Kinondoni Municipal Council (KMC) in Tanzania. The study adopted a case study research design and used questionnaires, in-depth interview and documentary review in data collection. The Sample size was 100 respondents selected through purposive sampling and the content analysis and cross tabulation methods were used in data analysis. The major study findings indicate that there was a weak implementation of OPRAS because there was no communication of the needs for OPRAS to employees, provision of OPRAS related training, and motivations to public servants were inadequately addressed. Furthermore, in local government authorities (LGAs) particularly KMC, there has been very little concern, demonstrated by inadequate funds and mechanisms put in place that ensure its implementation is effective and sustainable. In regard to this, the findings demonstrated an absence of viable efforts in terms of plans and strategies set to establish an effective and sustainable implementation of OPRAS in the KMC. The financial constrains caused by the absence of a specific budget for OPRAS implementation, laxity of the management in monitoring the implementation of OPRAS in the $\mathrm{KMC}$, as well as inadequate funds disbursed by the central government to KMC are the major factors restraining the effective implementation of OPRAS in the KMC. It is therefore concluded that there is a need for the government to strictly adhere to the processes required in the implementation of OPRAS, such as com-

(C) St. Petersburg State University, 2021 
municating the need for OPRAS to public servants and setting adequate funds for OPRAS to be conducted.

Keywords: open performance review, performance appraisal, local government staff performance, management.

\section{Introduction}

Open Performance Review and Appraisal System (OPRAS) originated from the performance management system (PMS) which existed worldwide, after the reforms that took place before 1950s in organizations, being used as a tool of the performance appraisal system which continued to be a subject of importance and interest among human resource specialists. Due to such importance, the research on performance appraisal has been carried out in developed countries, particularly the United States and some parts in Western Europe [1].

Following the continued use of the performance management system worldwide and its introduction in Tanzania in late 1980s, led to implementation of a number of reforms such as the civil Service Reform Programme (CSRP) from 1991-1998 and later the public service reform programme (PSRP) in 2000. The PSRP came with the introduction of OPRAS in 2004 as a new innovation for managing individual performance in the public service institutions. The PSRP incorporated the use of OPRAS as one of the major instruments for implementation of the Performance Improvement Model which was considered as a significant model to the adoption and nurturing of the performance management in the public Service [2].

In the context of public service reforms in Tanzania, the last decade of the $20^{\text {th }}$ century experienced introduction of public sector reform programmes inclined to the doctrines of the New Public Management (NPM). The Civil Service Reform Programme (CSRP) launched in July, 1991 and implemented at the onset of 1993 up to 1998, focused at cost containment and restructuring of government. With downsizing, rightsizing, retrenchment, and restructuring, the CSRP strived at creating a reasonably smaller, affordable, well-compensated, efficiently and effectively performing civil service for quality service delivery to the public [3].

The CSRP was succeeded by the Public Service Reform Programme (PSRP) which is implemented in a series of overlapping but mutually supporting phases [3]. The PSRP launched in 2000 has up to date been implemented in three distinct phases. The first phase that was implemented from 2000 to 2007 embarked on the installation of Performance Management Systems (PMS) in all MDAs, Regional Secretariats and LGAs. The main objective of this phase was to improve accountability, transparency and resource management for efficient and effective delivery of quality services to the public [4]. The second implementation phase of the PSRP that commenced from 2007 to 2012 targeted at enhancing performance and accountability while the on-going third phase of its implementation commenced from 2012 and lasted in 2017 which is envisioned on quality improvement cycle [3].

Under the theme of improving accountability, transparency and resource management, the government of Tanzania introduced public service reform through the PSRP. According to Issa, the installation of PMS in the public service aims at having a place predictable, effective and efficient system for planning, implementation, monitoring, evalua- 
tion and reporting in the public service in Tanzania [3, p. 5]. The overall objectives of these interventions, among other things, include the following: (a) providing quality services to the public, (b) improving performance of the public service institutions. The Open Performance Review and Appraisal System (OPRAS) as an open, formal, and systematic procedure designed to assist both employers and employees in planning, managing, evaluating and realizing performance improvement in the organization with the aim of achieving organizational goals. OPRAS has the following unique features that can be differentiated from the previous confidential appraisal system: openness of OPRAS allows both employee and employer to discuss and agree on the organizational and individual objectives that are to be achieved during the year openly [4].

The introduction of OPRAS in the Tanzania public service in July, 2004 had its roots in the PSRP (I) which installed PMS for the purpose of improving accountability, transparency and human resource management in search for good performance and quality service delivery in the public service. The overall objective of introducing OPRAS was to build an integrated system for creating a shared vision, understanding and agreement about the results to be achieved and the operational framework for continuous performance improvement standards and quality of public service delivery [2].

The installation of OPRAS in Tanzania replaced the traditional Confidential Performance Appraisal System (CPAS) which failed to promote performance improvements and accountability in the public service due to its inherent weakness in providing performance feedback and its inherent inability to identify employees' real strength, weaknesses and opportunities. The CPAS failed to capture a consistent and rationally designed framework for employees' training needs and promotions, thus, contributed to increased employees' complaints and grievances [4].

Furthermore, OPRAS is contended to be so instrumental in determining employees' eligibility for training and development, promotions, demotions, performance-based disciplinary actions and termination [5]. It offers a consistently rational and scientific process of identifying employees' capabilities, opportunities and the magnitude of the gaps for immediate intervention, thus, reducing employees' complaints and grievances as compared to the traditional closed system of appraising employees.

In building a well committed, accountable and result-oriented workforce in the public service, OPRAS was introduced as a performance measurement instrument by the government aiming at installing a performance oriented culture, behavior and attitudes among public servants for the purpose of improving performance in the public service. Such reform would ultimately facilitate a self-motivated and result-oriented performance management philosophy for improved accountability and responsiveness, efficiency and effectiveness in rendering quality services to the public [5].

Since July, 2004 the implementation of OPRAS in the Tanzania public service was, and still is, made mandatory for all MDAs, Regional Secretariats and LGAs through an establishment circular No. 2 of 2004 backed up by the Public Service Management and Employment Policy of 1999, Public Service Act No. 8 of 2002 and the Public Service Regulations of 2003 with their amendments [4]. The fact that OPRAS was installed in the public service in reform dimensions, it is therefore imperative to assess the process involving its implementation in the light of performance management, an aspect that has not been considered by other studies. Such a gap has left the problems facing its implementation uncured thus reducing the possibility of attaining its expected outcomes. 
In this regard, it is more than a decade since OPRAS was introduced in the Tanzania public service since July, 2004 to 2020 . The main purpose of introducing ORAS is to promote performance management that aim at advancing employees' performance towards improved public service delivery. The implementation of OPRAS could have been successful, thus, enabling assessment of its contribution to improved public service delivery in LGAs in Tanzania. However, experience indicates that the implementation of OPRAS in the Tanzania public service is yet to bring desired outcomes in LGAs [6]. More significantly, the assessments done on the implementation of OPRAS in Tanzania acknowledges that there exists a mismatch between the anticipated results and actual implementation of OPRAS in the course of service delivery in the public in LGAs. In that regard, the main focus of this paper is therefore to examine why is the implementation of OPRAS in the Tanzania public service not effective? Following the adoption of this tool in the performance management, this study attempted to explore the above stated gap by assessing the implementation techniques employed and exploring the challenges encountered in its implementation in public service at KMC. This paper therefore sets out to deal with the following research objectives:-i.to examine the rationale for ineffective implementation of OPRAS in the public service delivery in KMC in Tanzania, ii.to explore the challenges hindering implementation of OPRAS in KMC in Tanzania. The research questions thought to be answered are: Why is the implementation of the OPRAS in local government Authorities in Tanzania particularly KMC not effective as well as what are the challenges constraining an effective implementation of OPRAS in the public service?

\section{Empirical literature review}

Effective OPRAS implementation means the degree to which objectives of OPRAS are achieved and targeted problems related to OPRAS are resolved. Around 1980s to date, the public sector in many countries around the world has been experiencing public sector related reforms inclined to the NPM doctrines. Most of the reforms undertaken targeted at building a result-oriented management system that would facilitate performance improvement to improve public service delivery. In particular, Tanzania started undertaking reform initiatives to improve service delivery in the public sector since the last decade of the $20^{\text {th }}$ century. This period is marked by CSRP and PSRP launched in 1991 and 2000 respectively. In the context of these reforms with specific inference to the PSRP, the most remarkable reform undertaken in Tanzania is the introduction of OPRAS in July, 2004. This paper presents a detailed review of related literature on the discourse of performance management and deeper understanding on how OPRAS ought to be managed effectively and sustainably implemented. Nevertheless, a comparative experience with implementation of OPRAS is also discussed in this study.

\section{OPRAS forms' components and filling process}

OPRAS is an acronym for the words "Open Performance Review and Appraisal System". It is an open, formal and systematic procedure designed to assist both employers and employees in planning, managing, evaluating and realizing performance improvements in organizations with the aim of achieving organizational goals [4]. OPRAS requires supervi- 
sors and employees to critically develop commonly agreed performance objectives, targets as well as performance criteria.

Generally, OPRAS form is a document composed of eight (8) sections. Section one captures the general information of employees and their institutions. Section two is about performance agreement which is to be filled by the appraisee in consultation with the supervisor. The main parts of this section are the agreed objectives, agreed performance targets, agreed performance criteria and the agreed resources. Section three focuses on the mid-year review (dealt in December) aiming at seeing the progress toward meeting the targets and identifying the factors affecting performance. On the other hand, section four focuses on revising objectives if there is a need while section five focuses on annual performance review which is done in June.

Section six of the OPRAS forms contains attributes of good performance that are used in assessing employees. These attributes include working relationships, communication and listening, management and leadership, quality performance, responsibility and judgment, customer focus, loyalty, and integrity. Section seven shows the performance grades while section eight presents the relevant rewards, developmental measures and/or sanctions that an employee deserves from the grades he/she gets after being assessed.

According to the Standing Orders for the Public Service (2009), employees are required to fill OPRAS forms every $1^{\text {st }}$ July of each year. The guidelines purport that, the process of filling OPRAS forms requires employees and their respective supervisors to commonly agree on the performance objectives, targets and criteria in order to attain the desired goals. After filling the OPRAS forms on $1^{\text {st }}$ July, a mid-year review is done in December to check the level of progress in accomplishing the commonly agreed objectives. Finally, an annual review is done in June to assess the implementation status of the agreed objectives and other individual attributes as directed by the guidelines.

The final performance assessment grades that are subject to rewards, developmental measures or sanction as described in the OPRAS guidelines are, however, rated within five indicators of performance. The first grade implies an outstanding performance while the second-grade stands for performance above average, and the third grade indicates average performance. Nevertheless, grade four stands for poor performance while grade five implies very poor performance.

\section{Performance management practices}

In pursuit of performance improvement for quality service delivery in the public sectors, New Public Management (NPM) emphasizes on the adoption of private sector practices in public institutions (Furthermore, academics and practitioners continue to arrive at conclusions about performance management based on erroneous or obsolete information [7]. The NPM model shifts the emphasis from traditional public administration to public management and entrepreneurship, pushing public sectors towards managerialism for public service improvements in the public sector [7].

Many countries in Africa as contended by Waal, have been implementing PMS with varied level of success [8]. A study by Mothusi, on the installation of PMS in Botswana for example provides a clear background on the reform management practices in African countries. Mothusi adopted Kurt Lewin's Field Force Analysis in assessing the implemen- 
tation of PMS in Botswana in a change perspective. The study adopted a case study design focusing on four government departments in Botswana: two from the Ministry of Local Government and two from the Ministry of Lands and Housing [9].

Findings from that study reveal reform management in Botswana through installation of PMS is not effective. One of the most challenges highlighted by Mothusi in the study is that the adoption of top-down approach has been a challenge towards effective implementation of PMS in Botswana. Also, findings confer that an ineffective implementation of PMS in Botswana was caused by inadequate training among staff and negative attitude as there are staff who simply do not want to embrace PMS as it is not important as articulated. Nevertheless, lack of commitment of the management in the implementation of such PMS has been contributing to inadequate attainment of the desired change in Botswana.

However, the gap that exists between this study and that by Mothusi lies in the context at which the two studies are conducted and the type of PMS adopted in analyzing change. It is beyond reasonable doubt that Tanzania and Botswana are two different countries thus the findings obtained in Botswana cannot be generalized in Africa and Tanzania in particular. In that regard therefore, this study remains significant in exploring and assessing the rationale for ineffective implementation of OPRAS in Tanzania public service and the challenges facing it.

In Tanzania public service, a strategic effort for performance management dates as far back to the year 2000 when performance management systems were introduced under the PSRP (I). A more pronounced effort towards effective performance management anchored upon NPM and change initiatives was undertaken through an introduction of OPRAS in July, 2004 for enhancing performance in the public sector [6; 10]. OPRAS was introduced through an establishment of circular No. 2 of 2004 and made mandatory to all MDAs, Regional Secretariats and LGAs. It is further noted by Issa, that the implementation of OPRAS in the Tanzania public service is anchored upon policy and legal framework [6]. The rationale for introducing OPRAS in the Tanzania public service was to cultivate a performance by developing a result-oriented management philosophy among employees that could transform employees' performance behavior and attitudes for quality service delivery [11].

Since OPRAS was introduced in the public service in Tanzania, the government has been struggling to ensure that there is an effective implementation of OPRAS to meet the targeted objectives which is changed performance-culture for public service improvements. However, experience reveals that the implementation of OPRAS in the Tanzania public service is yet to be sustainably effective $[10 ; 12]$. As Waal noted, many Countries have experienced performance management initiatives but most of these were limited to the introduction of performance-oriented staff appraisal systems. These have not been very successful because in these systems, promotions are linked to performance while in many developing countries promotion is still linked to seniority or relations [8]. Furthermore, Mishra adds that performance appraisal is perceived by employees as more accurate and more reflective of their performance. They are thus considered as quite effective in providing comprehensive information [1].

Most of the studies conducted to evaluate the implementation of OPRAS in the Tanzania public service reveal that its implementation has not been in a desirable state thus the outcomes expected may not be attained. Laanyuni, for example conducted a study to assess the extent by which OPRAS is effectively been implemented in Mainland 
Tanzania specifically in the four ministries namely the Ministry of Finance and Economic Affairs (MoFEA), Ministry of Health and Social Welfare (MHSW), Ministry of Agriculture and Cooperative (MOAC) and the Ministry of Infrastructure Developments (MID) [13]. The findings from this study indicate that OPRAS has not been effectively implemented and that its implementation was not understood with sufficient clarity and consistency among these Ministries. The gap underlying the above findings in relation to this study lies within the setting under which the two studies are conducted and the theoretical perspective guiding them. Unlike the fore mentioned, this study was conducted in the local government authority and it employed the performance management in assessing the implementation of OPRAS. Furthermore, in Kenya, research by Muli sought to determine the impact of performance appraisal on secondary school teacher professional development in Kitui West District [14]. Apparently, none of the studies have been done to investigate the implementation of OPRAS to Local government staff performance. Therefore this study sought to fill the gap using KMC as a case in point.

\section{Research methods}

This study employed both qualitative and quantitative research methodologies in collecting and analyzing information to illuminate coherence in discussion and conclusion. However, this study holds that, the best research is that which involves a combination of these methodologies.

The study area for this study was KMC which was purposefully selected among 169 LGAs in Tanzania. The reason behind this selection was based on the following reason: The assessment reports on OPRAS implementation status in the Tanzania LGAs by the Tanzania Public Service Commission (TPSC) reveals that KMC is one of those councils that were not performing well [5]. This has attracted attention to the researcher to investigate ineffectiveness of OPRAS implementation in KMC in Tanzania.

The target population for this study through which data were collected was basically the KMC staff. The data were collected from a total number of 100 respondents of whom 10 respondents constituted the Heads of Departments (HODs) whose responsibilities is to ensure OPRAS is effectively implemented in their respective departments and 90 respondents constituted ordinary staff. The 10 heads of departments were purposefully selected given the number of employees they supervise. Table 1 below presents the sample size and its composition.

This study employed purposive sampling technique in selection of respondents who were ordinary staff and heads of departments. This was done mainly to enable the study have a good and reasonable number of respondents to represent the whole council.

The methods of data collection were an in-depth interview was employed to collect data from 10 heads of departments at KMC who were picked from 10 purposively selected departments in order to obtain detailed information for the study. An in-depth interview was adopted to HODs for the purpose of collecting adequate information from them as they are the one responsible for ensuring that OPRAS is effectively implemented in their respective offices. Furthermore, questionnaires were administered to collect data from 90 ordinary staff respondents selected purposively from 10 departments as listed in Table 1 and explained above. The application of this method in col- 
lection of data was important in reaching a large number of respondents in a short period of time. On the other hand, the usage of questionnaires helped in collecting the quantifiable data for this study. Similarly, various documents were reviewed to facilitate a deeper understanding to the matter in question. Documents reviewed include but not limited to the following: government reports, guidelines on the implementation of OPRAS and other relevant information obtained from the council related to the topic under the study.

Table 1. Sample distribution and sample size

\begin{tabular}{|l|l|c|c|}
\hline \multirow{2}{*}{ No. } & \multicolumn{1}{|c|}{ Name of Department } & \multicolumn{2}{|c|}{ Total No. of respondents } \\
\cline { 3 - 4 } & & $\begin{array}{c}\text { Local } \\
\text { government } \\
\text { staff }\end{array}$ & Percentage \\
\hline 1 & Primary Education Department & 40 & 40 \\
\hline 2 & Human Resource and Administration Department & 20 & 20 \\
\hline 3 & Works Department & 5 & 5 \\
\hline 4 & Health Department & 10 & 10 \\
\hline 5 & Secondary Education Department & 15 & 15 \\
\hline 6 & Land and Urban Planning & 2 & 2 \\
\hline 7 & Agricultural and Cooperatives Department & 2 & 2 \\
\hline 8 & Community Development Department & 2 & 2 \\
\hline 9 & Finance Department & 2 & 2 \\
\hline 10 & Livestock Department & 100 & 100 \\
\hline Total number of respondents & & \\
\hline
\end{tabular}

Source: Field data (April, 2020).

In analyzing the data collected from the field, this study employed both qualitative and quantitative analysis. Content analysis was adopted in analyzing the data obtained from documentary review, in-depth interviews and cross tabulation was used in data collected through questionnaires. Under Content analysis technique, data were systematically classified into defined categories comprising patterns of related information sub-themes. For instance, rationale for ineffective implementation of OPRAS was classified into their sub-categories such as abysmal communication of OPRAS to the employees. This method of data analysis facilitated the making of inferences from the qualitative data. On the other hand, with the aid the Statistical Package for Social Sciences (SPSS), descriptive statistics (tabulation) technique and cross-tabulation were used to analyze the quantitative data that were mainly obtained from questionnaires. 


\section{Presentation and discussion of the findings}

\section{Respondents' socio-economic characteristics}

\section{Respondents' age}

From the data collected, 5 (5\%) of the respondents belong to the age group below 30 years and $90(90 \%)$ respondents belong to the age group between 30 to 45 years while the remaining $5(5 \%)$ respondents were above 45 years. Table 2 below presents the age categories of the respondents as well as the number of respondents and their respective percentages. The findings gives the impression that most of respondents were aware of the challenges in the implementation of the OPRAS since it started in 2004 to 2020.

Table 2. Respondents' age distribution

\begin{tabular}{|l|l|c|c|}
\hline S/N & \multicolumn{1}{|c|}{ Age categories of respondents } & $\begin{array}{c}\text { No. of } \\
\text { respondents }\end{array}$ & Percentage \\
\hline 1 & Below 30 years & 5 & 5 \\
\hline 2 & Between 30 to 45 years & 90 & 90 \\
\hline 3 & Above 45 years & 5 & 5 \\
\hline \multicolumn{2}{|l}{ Total number of respondents } & 100 & 100 \\
\hline
\end{tabular}

Source: Field data (April, 2020).

\section{Respondents' gender}

The data collected on respondents' gender indicates that 50 respondents which is equivalent to $50 \%$ are male while 50 respondents which is equivalent to $50 \%$ are female. Table 3: below shows respondents' gender in terms of frequency and percentages as demonstrated above. The findings in this study indicate that both male and female respondents perceived that OPRAS was not communicated to the employees regardless of their gender. (See table 3 below.)

Table 3. Respondents' gender

\begin{tabular}{|c|c|c|c|}
\hline $\mathrm{S} / \mathrm{N}$ & Gender & Frequency & Percentage \\
\hline 1 & Male & 50 & 50 \\
\hline 2 & Female & 50 & 50 \\
\hline \multicolumn{2}{|l|}{ Total } & 100 & 100 \\
\hline
\end{tabular}

Source: Field data (April, 2020).

The findings of this study differ from Dimeglio, who notes that using content analysis of individual annual performance reviews, shows that women were 1.4 times more likely to receive critical subjective feedback (as opposed to either positive feedback or critical objective feedback to men). This was due to the fact that annual evaluations are often subjective, which opens the door to gender bias [15]. 


\section{Respondents' level of education}

The data collected on respondents' level of education portray that $52(52 \%)$ of the respondents are degree holders and above, and $48(48 \%)$ were diploma holders. The education level of respondents was very necessary in this study in order to get views and opinions from respondents with different levels of education.

\section{Respondents' working experience}

Under this aspect, the data collected indicate that none of the respondents had served for the public service for the period ranging from 6 months to 2 years and $12 \%$ had served for a period ranging from 3 to 6 years. On the other hand, $27 \%$ of the respondents had served for a period ranging from 3 to 6 years while $48 \%$ had served for from 7 to 10 years and $40 \%$ of respondents served for more than 11 years. Table 4 presents the respondents' years of public service in terms of frequencies and percentages. The findings indicate that there were majority of employees i.e. 88 respondents as presented in table 4 had working experience of more than 7 years that could help to provide valid information about OPRAS at KMC which indicates that the data were collected from respondents with vast working experience with regard to OPRAS.

Table 4. Respondents' years of working experience

\begin{tabular}{|l|l|c|c|}
\hline \multicolumn{1}{|c|}{ S/N } & \multicolumn{1}{|c|}{ Duration of working experience } & Frequency & Percentage \\
\hline 1 & 6 months to 2 year & 00 & 00 \\
\hline 2 & 3 to 6 years & 12 & 12 \\
\hline 3 & 7 to 10 years & 48 & 48 \\
\hline 4 & 11 years and above & 40 & 40 \\
\hline \multicolumn{2}{|l|}{ Total number of respondents } & 100 & 100 \\
\hline
\end{tabular}

Source: Field data (April, 2020).

\section{Assessing OPRAS institutionalization process in the public service}

This section presents, analyzes and discusses the findings based on the first objective that aims at assessing OPRAS implementation process in the public service. However, the analysis focuses on communicating the rationale for implementing OPRAS to the employees, inspiration of employees to implement OPRAS, involvement of employees in implementing OPRAS at KMC, OPRAS training to employees, OPRAS incentives and motivation to employees.

\section{Communicating the needs for OPRAS at KMC departments}

Communicating the need for OPRAS is explicitly one of the important aspects ought to be considered in introduction of the OPRAS. In this study, a question was set to explore employees' opinion on the extent to which the rationale for introduction of OPRAS in the public service was communicated to the public servants as one of the key aspects in the process of introducing public sector reform. Table 5 presents the responses on the extent to which the needs for the introduction of OPRAS in the public service were communicated to employees in at KMC. 
Table 5. The extent OPRAS Objectives were communicated to employees at KMC

\begin{tabular}{|l|l|c|c|}
\hline \multicolumn{1}{|c|}{ S/N } & \multicolumn{1}{|c|}{ Responses } & Frequency & Percentage \\
\hline 1 & Very sufficiently communicated & 10 & 10 \\
\hline 2 & Satisfactorily communicated & 25 & 25 \\
\hline 3 & Inadequately communicated & 50 & 50 \\
\hline 4 & Not communicated & 10 & 10 \\
\hline 5 & Do not know & 5 & 5 \\
\hline \multicolumn{2}{|l|}{ Total number of respondents } & 100 & 100 \\
\hline
\end{tabular}

Source: Field data (April, 2020).

The findings presented in table 5 above indicates that $50(50 \%)$ of the respondents reported that the objectives for the introduction of OPRAS in the public service were inadequately communicated among KMC employees, $10(10 \%)$ argued that such objectives were not communicated at all. Moreover, the other $10(10 \%)$ respondents contented that the objectives were sufficiently communicated while $10(10 \%)$ respondents argued that the objectives were very sufficiently communicated. The remaining 5 (5\%) of the respondents said they do not know anything about the OPRAS.

From the data presented above, findings demonstrate that the need for the introduction of OPRAS in the public service was inadequately communicated among public servants in the KMC. This is demonstrated by $50 \%$ as it evidently appears in the table 5 above. The most contended reason as to why the need for the introduction of OPRAS at KMC was inadequately communicated among employees in the KMC as provided by the management was strongly tied to inadequate financial resources for disseminating such performance evaluation tool. For instance, in 2009/2010, the budgeted amount to be collected was Tshs. 5,052,573,979.00/= but the actual amount was Tshs. 3,914,141,219.00/=, equivalent to $77 \%$ and in 2013/2014, the budgeted amount to be collected was Tshs. 62,661,106,227.66/= but the actual amount was Tshs. 34,187,515,338.99/=, equivalent to 55\% (KMC's Revenue Collection Reports from 2008/2009 to 2017/2018). The findings corroborate with dimeglio, who notes that training appraisers give feedback about specific criteria that the employer and employee agree too may not be successful due inadequate funds [15].

\section{Inspiring employees to embrace OPRAS}

In assessing OPRAS implementation process in the public service, a question was also set to explore the extent to which employees were set ready to embrace the application of OPRAS in the public service. The basic assumption was that organization members would embrace and implement well the OPRAS if they are highly inspired to do so by the management.

The Findings presented in Table 6 indicate that, 90 (90\%) of the respondents argued employees were insufficiently inspired to eagerly embrace the application of OPRAS at KMC while $2(2 \%)$ commented that employees were not inspired at all. On the other hand, $2(2 \%)$ contended that employees are sufficiently inspired, and $2(2 \%)$ argued employees are very sufficiently inspired to embrace the implementation of OPRAS. The remaining $4(4 \%)$ respondents argued they do not know. Table 6 below presents the findings in summary. 
Table 6. The extent employees were inspired to implement OPRAS at KMC

\begin{tabular}{|l|l|c|c|}
\hline S/N & \multicolumn{1}{|c|}{ Responses of respondents } & Frequency & Percentage \\
\hline 1 & Very adequately inspired & 2 & 2 \\
\hline 2 & Sufficiently inspired & 2 & 2 \\
\hline 3 & Insufficiently inspired & 90 & 90 \\
\hline 4 & Not inspired at all & 2 & 2 \\
\hline 5 & Do not know & 4 & 4 \\
\hline Total number of respondents & 100 & 100 \\
\hline
\end{tabular}

Source: Field data (April, 2020).

The finding presented in table 6 indicate that employees in the KMC are insufficiently inspired to eagerly embrace the application of OPRAS in the public service with particular inference to the KMC as demonstrated by $90 \%$ of the respondents. Basically, any reform initiative in an organization needs to seek support from organization members. In other words, no institutional and legal reform in an organization can be successful without getting support from the organization members. Such support is only possible where there are serious initiatives undertaken to inspire organization members to eagerly embrace such reform.

Furthermore, Piderit notes that the success of any public sector reform initiative in an organization depends on the extent to which organization members are set ready to welcome such changes [16]. Experience demonstrates that no reform in organizations have been successful without support from organization members. An insufficiency degree of inspiring employees to eagerly embrace the application of OPRAS in the public service demonstrated by the findings which suggest a weak implementation of OPRAS in the KMC. In that regard, the implementation of OPRAS in the KMC may be susceptible to various forms of resistance from employees. These findings do not corroborate with URT which notes that importance of process which promotes individual accountability, improved transparency and communication between management and employees [17]. The study disagree with Down, which notes that sense of ownership and the understanding of appraisal process are noted as a factor in making an appraisal system more effective [18]. Therefore, for effective implementation of OPRAS, it is important for supervisors and supervisee to set and agree together on the objectives to be accomplished on such specific period.

\section{Involvement of employees in implementing OPRAS at KMC}

In examining the involvement of employees in implementing OPRAS in the public service, one question was asked to respondents: intending to identify the extent they were involved in decisions related to OPRAS implementation in the public service. The findings indicate that, 65 (65\%) of the respondents said that employees were not involved in decisions related to OPRAs implementation and 20 (20\%) respondents had the view that they were not involved in decisions related to OPRAS implementation. On the other hand, 15 (15\%) said that they did not know about OPRAS implementation. Table 7 below presents the findings in detail. 
Table 7. The extent to which employees were involved in OPRAS related decisions

\begin{tabular}{|l|l|c|c|}
\hline S/N & \multicolumn{1}{|c|}{ Responses } & $\begin{array}{c}\text { Number } \\
\text { of responses }\end{array}$ & Percentage \\
\hline 1 & $\begin{array}{l}\text { Employees were involved in decision related to OPRAS } \\
\text { implementation }\end{array}$ & 20 & 20 \\
\hline 2 & $\begin{array}{l}\text { Employees were not involved in decisions related to } \\
\text { OPRAS implementation }\end{array}$ & 65 & 65 \\
\hline 3 & Do not know & 15 & 15 \\
\hline \multicolumn{2}{|l|}{ Total number of respondents } & 100 & 100 \\
\hline
\end{tabular}

Source: Field data (April, 2020).

Inferring from the findings as shown above, it is noted that employees were not involved in implementing OPRAS instead OPRAS was dictated to them by the government in implementing and such approach was perceived inappropriate by employees in ensuring employees compliance as demonstrated by $65(65 \%)$ of the respondents. However, studies in the field of performance management indicate that lack of participation in implementation of reforms does not conform to the new practices in the today's organizations characterized by democratic practices demonstrated in the information-rich and knowledge-intensive environment [19]. In similar case, these findings contravenes with the OPRAS implementation guideline stated in URT which notes that "OPRAS involves employees in the process of setting objectives, performance targets and criteria as well as determining, assessing and recording performance" [4].

\section{OPRAS Training to employees in KMC}

Since reforms in organizations are associated with training focusing at exposing organization members to the new values and practices of doing business, the introduction of OPRAS imperatively demands intensive training to employees for a successful and sustainable application. In that regard, a question was set to explore the extent OPRAS related training is provided to KMC employees in the course of its implementation. From the data collected, findings give impression that, $50(50 \%)$ of the respondents revealed that there was no training provided to employees by the KMC while 25 (25\%) contended that training was insufficiently provided to employees. Only $10(10 \%)$ and $15(15 \%)$ of the respondents argued for sufficient and very sufficient OPRAS training provided to employees by the KMC respectively.

The findings indicate that OPRAS being a new tool of appraising employees' performance in the public service, it appears that, no serious attention has been given to OPRAS training by the KMC management to employees. Since training is conducted for the purpose of enhancing good performance and building employees' capacity on the technical know-how to apply such a system in performing duties assigned, the absence or an insufficiency OPRAS training to employees as demonstrated by the findings which provide a ground predictable for hardships in implementing such a system. Usually, OPRAS related training needs to be offered to the organization members more frequently so as to sharpen their understanding on how the system works. Since the public service keeps on recruiting new members in every financial year, these members need to be oriented to the applica- 
tion of OPRAS regularly. In this regard, OPRAS training need to at least be provided once every financial year to specific groups of employees as it may be required. From the data collected this has not been the case in the KMC.

Moreover, data collected through an in-depth interview from Head of Departments reveals also that OPRAS training to employees in the KMC is not consistently done. As main OPRAS supervisors in their respective departments, 8 (80\%) Heads of departments out of all 10 acknowledged that OPRAS related training is inadequately provided to KMC employees with invariably a couple of reasons such as inadequate funds and lack of commitment to the implementation of the OPRAS.

The findings corroborate a documentary review which included the council MTEF and CBG implementation reports for the past four (4) years $(2014 / 2015,2015 / 2016$, 2016/2017 and 2017/2018, 2018/2019). The review found out that in the council MTEF as a budget document, no specific budget items relating to OPRAS was budgeted for the whole period of five (5) years though claimed to have been budgeted as a subset within the training items. Thus, this creates discretionary power to the municipal directors to decide what kind of training should be conducted based on the meager fund available. On the other hand, for the past three years the Capacity Building Grants implementation reports showed that OPRAS trainings were conducted to only 102 employees in the administration department for the year 2015/2016. From the documents reviewed including Standing Committees Meetings, for the past four years as identified above no any other OPRAS training was conducted to the KMC employees apart from that of 2015/2016 done to 102 employees in the department of administration.

\section{OPRAS incentives and motivation to employees}

Motivation is one of the techniques employed in performance management and the question was set in this study to examine whether the implementation of OPRAS in the public service is associated with any motivation. Table 8 presents the findings in details.

Table 8. Presence of OPRAS related motivation to employees

\begin{tabular}{|l|l|c|c|}
\hline \multicolumn{1}{|c|}{ S/N } & \multicolumn{1}{|c|}{ Respondents' responses } & $\begin{array}{c}\text { Number of } \\
\text { responses }\end{array}$ & Percentage \\
\hline 1 & OPRAS related motivation was present & 20 & 20 \\
\hline 2 & OPRAS related motivation was not present & 60 & 60 \\
\hline 3 & Do not know & 20 & 20 \\
\hline \multicolumn{2}{|l}{ Total number of respondents } & $\mathbf{1 0 0}$ & $\mathbf{1 0 0}$ \\
\hline
\end{tabular}

Source: Field data (April, 2020).

From the data presented in table 8 above, $60(60 \%)$ of all 100 respondents had the view that the implementation of OPRAS in the KMC is not linked to any motivation and $20(20 \%)$ were not aware of whether there are any motivations provided to employees in the process of executing OPRAS while $20(20 \%)$ contended that the implementation of OPRAS in the KMC is linked to motivation. It was noted that an implementation of OPRAS at KMC was further hindered by poor motivation to employees in implementing it. Lack of motivation such as incentives to the employees who scored excellent per- 
formance in the process of implementing such a tool at KMC caused ineffectiveness in implementation of it.

\section{Monitoring and Evaluation of OPRAS execution at KMC}

OPRAS execution process demands a high degree of members' commitment in monitoring and evaluating the process. However, monitoring and evaluation is a function of the organization top management. In assessing the level at which OPRAS monitoring and evaluation is done at KMC, this study focused on assessing how committed is the KMC top management in implementing OPRAS. The Table 9 presents the findings in details.

Table 9. Responses on commitment of the Management in supervision of OPRAS

\begin{tabular}{|l|l|c|c|}
\hline \multicolumn{1}{|c|}{ S/N } & \multicolumn{1}{|c|}{ Responses } & $\begin{array}{c}\text { Number of } \\
\text { responses }\end{array}$ & Percentage \\
\hline 1 & Very committed & 10 & 5 \\
\hline 2 & Not committed at all & 5 & 10 \\
\hline 3 & Poorly committed in monitoring OPRAS & 75 & 75 \\
\hline 4 & Very committed & 10 & 10 \\
\hline 5 & Do not know & 0 & 0 \\
\hline \multicolumn{2}{|l}{ Total number of respondents } & 100 & 100 \\
\hline
\end{tabular}

Source: Field data (April, 2020).

Findings from the table 9 above reveal that 75 (75\%) of the respondents said that that the top management of the KMC is poorly committed in monitoring OPRAS implementation process. On the other hand, 5 (5\%) respondents said that KMC top management is not committed at all in monitoring OPRAS implementation process while $10(10 \%)$ respondents said that the top management is committed and only 10 (10\%) of respondents said that the top management is very committed in monitoring such implementation. None of respondents said that they do not know.

The findings provided above demonstrate that, there is little attention given by the KMC top management to serious implementation of OPRAS demonstrated by 75 (75\%) marked poor commitment. Principally, no reform can be successful if the implementation of such reform is not seriously monitored. The organization top management as the main supervisors of the reform initiative is responsible for ensuring that it is effectively implemented. In that regard, lack of seriousness in monitoring OPRAS execution by the KMC top management as revealed by the findings above suggest that OPRAS implementation in the KMC is poor as employees need to be supervised for them to implement it well.

Such findings correspond with that of Bana, who notes that the implementation of OPRAS in the Tanzania public service has been patchy with a minimal rate of compliance among public servants and that there is a skeptical role among public servants and the management towards its implementation [10]. This implies that there is little concern in monitoring the implementation of OPRAs in the KMC thus causing hardships in the general implementation process of this tool. 


\section{Assessing employees' compliance to OPRAS implementation}

In assessing employees' compliance to the implementation of OPRAS in the public service, two key issue areas were explored in this study. At one point the researcher enquired to know whether employees fill the OPRAS forms on time as prescribed in the OPRAS application guidelines and on the other hand it assessed employees' willingness to continue using OPRAS in executing their functions. Focusing on these two issues, the data collected are presented and discussed in details below.

\section{Timely filling of OPRAS forms}

Employees' compliance on OPRAS implementation process can be assessed through OPRAS forms filling. In this regard, the study examined whether employees in the KMC fill OPRAS forms on time as prescribed in the OPRAS and Standing Order guidelines and the findings are as displayed in the table 10 below.

Table 10. Responses on timely filling of OPRAS Forms at KMC

\begin{tabular}{|l|l|c|c|}
\hline \multicolumn{1}{|c|}{ S/N } & \multicolumn{1}{|c|}{ Responses } & Frequency & Percentage \\
\hline 1 & OPRAS forms were filled on time & 5 & 5 \\
\hline 2 & OPRAS forms were not filled on time & 90 & 90 \\
\hline 3 & Do not know & 5 & 5 \\
\hline \multicolumn{2}{|l|}{ Total number of respondents } & 100 & 100 \\
\hline
\end{tabular}

Source: Field data (April, 2020).

The findings as indicated in the table 10 above reveal that, 90 (90\%) of the respondents argued that employees do fill OPRAS forms on time and 5 (5\%) of respondents said that employees do not fill OPRAS forms on time while the remaining $5(5 \%)$ of the respondents argued they do not know whether employees fill OPRAs forms on time i.e. on the first of July. In that regard, the findings demonstrate that the level of employees' compliance to OPRAS implementation in KMC is relatively high marked up by $90 \%$. The findings reveal that OPRAS is being used by the KMC in appraising employees' performance as mandated through an established circular No. 2 of 2004.

On the other hand, findings on the extent employees fill OPRAS forms timely as depicted in table 10 showing that only $5 \%$ of employees being filling OPRAS forms on time reveal that the implementation of OPRAS in the KMC is weak. It is however worth noting that the worthiness of the application of OPRAS whatsoever rests on the extent to which it is applied effectively and that if it is not, then it reduces its meaning. In this regard, such findings reveal that the application of OPRAS in the KMC is weak thus reducing the logic as well as the intended meaning of its application in the public service.

\section{Responses on whether OPRAS is compulsory tool for performance evaluation in KMC}

Respondents were asked to identify whether the application of OPRAS in the public service is compulsory or optional tool for performance evaluation. Responses indicated that, $80(80 \%)$ of the respondents out of all 100 responded that it was compulsory and 
only $10(10 \%)$ contended it was optional while the remaining $10(10 \%)$ respondents said that they do not know. The table 11 below indicates the findings in details.

Table 11. Responses on whether the application of OPRAS is compulsory or optional in KMC

\begin{tabular}{|l|l|c|c|}
\hline S/N & Item & Frequency & Percentage \\
\hline 1 & OPRAS is Compulsory & 80 & 80 \\
\hline 2 & OPRAS is Optional & 10 & 10 \\
\hline 3 & Do not know & 10 & 10 \\
\hline \multicolumn{2}{|l|}{ Total number of respondents } & 100 & 100 \\
\hline
\end{tabular}

Source: Field data (April, 2020).

The findings provided above demonstrate that the application of OPRAs in the public service was mandatory in the public service. In other words, the application of OPRAS is mandatory since its introduction in 2004, it was expected that all employees would have a clear knowledge concerning its application. In that regard, $10(10 \%)$ of the respondents said that its application is not compulsory and $10(10 \%)$ respondents said that they do not know which implies that inadequate dissemination of information concerning its application.

\section{OPRAS and decision making on employment matters at KMC}

The study also explored the extent OPRAS is being used in informing decision related to employment promotion and staff training in the public service. The findings demonstrated that, $10(10 \%)$ of the respondents said that they do not know about OPRAS and $70(70 \%)$ said that the results obtained from OPRAS were not used to inform decision making about local government staff in the KMC. On the other hand, 15 (15\%) of respondents said that OPRAS results are insufficiently used to inform decisions related to employment while $5(5 \%)$ said that the results are sufficiently applied. Based on the findings of this study, OPRAS in the public service particularly in the KMC is not adequately applied as a tool for decision making in regard to promotions, identification of training needs for employees' carrier development and others related to employment affairs such as motivation.

\section{Examining the challenges restraining OPRAS implementation in at $K M C$}

This part examines the challenges encountered in the implementation of OPRAS in the public service at KMC. In so doing, interviews and questionnaire as well as documentary review solicited the following challenges encountered in implementation of OPRAS in the public service as follows:-

The findings revealed that, insufficient OPRAS training to employees in the KMC is one of the challenges encountering the implementation of OPRAS. This was demonstrated by all $100(100 \%)$ of all 100 respondents. An insufficiency in provision of OPRAS training to employees as it was found in this study can be linked to multiple interpretations in the context of OPRAS implementation in the public service at KMC, one being 
employees' loss of morale in implementing this tool due to lack of knowledge on how to use it properly and hence become reluctant in filling OPRAS forms.

It also demonstrated by $90(90 \%)$ percent that lack of management commitment in monitoring the implementation of OPRAS in the KMC is the other challenge encountering the implementation of OPRAS while $10(10 \%)$ did not state any challenge. The organization top management is so instrumental in determining the success of any public sector reform initiative [8]. In other words, the success or failure of any change initiative in organizations depends on the extent that the organization management is determined in implementing such change. In that regard, laxity of the management in monitoring the implementation of OPRAS in the KMC provides justifiable grounds for ineffective running of this performance tool and thus the expected results may not be realized.

Another challenge as stated by respondents indicated that in KMC $60(60 \%)$ out of all 100 respondents as presented in table 12 cited the financial resources deficit as a major challenge in implementation of OPRAS in KMC (see table 12). Conversely, 40 (20\%) respondent said that the financial resources deficit was not a challenge to implementing OPRAS in KMC. These findings are presented in Table 12:

Table 12. Responses on financial deficit as a challenge to the implementation of OPRAS in KMC

\begin{tabular}{|c|c|c|c|c|c|}
\hline S/No & Category of respondents & $\begin{array}{l}\text { Financial } \\
\text { resource is } \\
\text { inadequate }\end{array}$ & $\begin{array}{l}\text { Financial } \\
\text { resource is } \\
\text { adequate }\end{array}$ & I do not know & $\begin{array}{l}\text { Total number } \\
\text { of respondents }\end{array}$ \\
\hline 1 & $\begin{array}{l}\text { Primary School Teachers } \\
\mathrm{N}=40\end{array}$ & $30(30 \%)$ & $10(10 \%)$ & 00 & $40(100 \%)$ \\
\hline 2 & $\begin{array}{l}\text { Human Resource and } \\
\text { Administration } \mathrm{N}=20\end{array}$ & $10(10 \%)$ & $10(10 \%)$ & 00 & $20(100 \%)$ \\
\hline 3 & Works Department $\mathrm{N}=4$ & $2(50 \%)$ & $2(50 \%)$ & 00 & $4(100 \%)$ \\
\hline 4 & Health Department $N=6$ & $3(50 \%)$ & $3(50 \%)$ & 00 & $6(100 \%)$ \\
\hline 5 & $\begin{array}{l}\text { Secondary Education } \\
\text { Department } \mathrm{N}=4\end{array}$ & $2(50 \%)$ & $2(50 \%)$ & 00 & $4(100 \%)$ \\
\hline 6 & $\begin{array}{l}\text { Land and Urban Planning } \\
\mathrm{N}=2\end{array}$ & $1(50 \%)$ & $1(50 \%)$ & 00 & $2(100 \%)$ \\
\hline 7 & $\begin{array}{l}\text { Agricultural and Cooperatives } \\
\text { Department } \mathrm{N}=2\end{array}$ & $1(50 \%)$ & $1(50 \%)$ & 00 & $2(100 \%)$ \\
\hline 8 & $\begin{array}{l}\text { Community Development } \\
\text { Department } \mathrm{N}=2\end{array}$ & $1(50 \%)$ & $1(50 \%)$ & 00 & $2(100 \%)$ \\
\hline 9 & Finance Department N $=6$ & $3(50 \%)$ & $3(50 \%)$ & 00 & $6(100 \%)$ \\
\hline 10 & Livestock Department $\mathrm{N}=4$ & $2(50 \%)$ & $2(50 \%)$ & 00 & $4(100 \%)$ \\
\hline 11 & Heads of Department $\mathrm{N}=10$ & $5(50 \%)$ & $5(50 \%)$ & 00 & $10(100 \%)$ \\
\hline \multicolumn{2}{|c|}{ Total number of responses } & $60(60 \%)$ & $40(40 \%)$ & 00 & $100(100 \%)$ \\
\hline
\end{tabular}

Source: Field data (April, 2020). 
The findings presented in table 12 are supported by documentary evidence from the KMC Revenue and Budget Reports for the financial years 2008/2009 to 2017/2018. The financial deficit is confirmed by the trend in the Central Government's disbursement of grants to $\mathrm{KMC}$ as presented in table 13:

Table 13. Trend in central government's disbursement of grants to KMC

\begin{tabular}{|c|c|c|c|}
\hline Financial Year & $\begin{array}{c}\text { Budgeted funds allocated to } \\
\text { municipal function in Tshs. }\end{array}$ & $\begin{array}{c}\text { Actual amount of grants } \\
\text { disbursed and allocated for } \\
\text { expenditure in Tshs. }\end{array}$ & $\begin{array}{c}\text { Percentage of } \\
\text { grants disbursed, } \\
\%\end{array}$ \\
\hline $2008 / 2009$ & $13,318,675,593.00$ & $10,319,357,405.71$ & 77 \\
\hline $2009 / 2010$ & $7,413,462,600.00$ & $12,598,373,594.00$ & 170 \\
\hline $2010 / 2011$ & $11,793,066,000.00$ & $11,974,840,001.34$ & 102 \\
\hline $2015 / 2016$ & $11,969,169,000.00$ & $13,890,024,698.00$ & 116 \\
\hline $2016 / 2017$ & $9,407,645,000.00$ & $9,407,645,000.00$ & 100 \\
\hline $2017 / 2018$ & $10,037,050,300.00$ & $9,452,211,170.12$ & 94 \\
\hline Total funds in Tshs. & $\mathbf{6 3 , 9 3 9 , 0 6 8 , 4 9 3 . 0 0}$ & $\mathbf{6 7 , 6 4 2 , 4 5 1 , 8 6 9 . 1 7}$ & 106 \\
\hline
\end{tabular}

Source: KMC's Revenue Collection Reports (2008/2009-2017/2018).

The revenue pattern depicted in table 13 indicates that the grants from the Central Government still constituted a large amount of the funds covering its expenditure. However, the Central Government funds disbursed were inadequate for some of the financial years. Sometimes, the disbursement of funds was delayed which hindered the following up and implementation of OPRAS. For example, KMC Revenue Collection Reports $(2019 ; 2018)$ note that in $2008 / 2009$, KMC got $77 \%$ of its budgeted revenue from Central Government grants, indicating a deficit of $33 \%$ which limited OPRAS implementation in KMC. The findings indicate that from 2008/2009 to 2017/2018, it did not collect all the revenue budgeted for which impinged on effective and efficient OPRAS management. For example, in 2008/2009, the budgeted amount to be collected was Tshs. $3,261,000,000.00 /=$, but the actual amount collected was Tshs. $1,743,950,369.00 /=$ or $53 \%$. In 2009/2010, the budgeted amount to be collected was Tshs. 5,052,573,979.00/= but the actual amount was Tshs. 3,914,141,219.00/=, equivalent to $77 \%$ and in $2013 / 2014$, the budgeted amount to be collected was Tshs. $62,661,106,227.66 /=$ but the actual amount was Tshs. $34,187,515,338.99 /=$, equivalent to $55 \%$ [20].

The findings corroborate with KMC revenue Collection Report (2018) which notes that in the 2017/2018 financial year, the actual amount collected was only $51 \%$, indicating that the revenue not collected amounted to $49 \%$. The revenue collection pattern shows that KMC encountered a deficit in revenue collection which caused financial constraints which hindered effective implementation of OPRAS.

From the findings discussed above, two things can be noted. First, the tendency of not setting specific budget for OPRAS training as it appears in the council Medium Term Expenditure Framework implies that the government does not give due and desirable attention for the implementation of OPRAS in the public service. 
Also, the discretionary power given to the Chief Executive Officers in determining the type of training as set in the council budget may implicitly hinder OPRAS training as it may not be the priority for the council. So much so, the insufficient OPRAS related training to employees in the KMC as found out above may spring from this aspect.

\section{Conclusion, recommendation, scope for further research and research limitations}

\section{Conclusion}

It is therefore, concluded that this study makes a profound contribution to the empirical literature on OPRAS as it reveals circumstances which hinder effective implementation of OPRAS such as inadequate funds and low involvement of employees in the implementation of the OPRAS at KMC. Furthermore, this study also contributes to knowledge on the subject of performance management especially on the challenges hindering effective implementation of OPRAS and it serves as a reference and basis for further research. More significantly, it provides an understanding of the efficacy of OPRAS in LGAs such as in KMC, and beyond because the results of this study show whether or not OPRAS implementation is a management strategy to improve performance in local governments in Tanzania.

Although the application of OPRAS in the public service is intended to build a resultoriented performance among public servants, the study found out that its implementation is weak because there was no communication of the needs for OPRAS to employees, provision of OPRAS related training, and motivations to public servants were inadequately addressed. Furthermore, in LGAs particularly KMC, there has been very little concern, demonstrated by inadequate funds, and mechanisms set, in ensuring that its implementation is effective and sustainable. In regard to this, findings demonstrated absence of viable efforts in terms of plans and strategies set to establish an effective and sustainable implementation of OPRAS in the KMC. The financial constrains caused by absence of specific budget for OPRAS implementation and laxity of the management in monitoring an implementation of OPRAS in the KMC as well as poor revenue collection and inadequate funds disbursed by the central government to KMC are the major factors restraining an effective implementation of OPRAS in KMC. This is demonstrated by insufficient OPRAS training provided to employees, non-timely filling of OPRAS forms by employees, non-reliant on OPRAS results in making decisions related to employment affairs like promotions and carrier development, poor dissemination/sharing of OPRAS objectives to employees.

\section{Recommendation}

In order to make OPRAS implementation effective, the study recommends the government to intentionally revisit the key elements that are inadequately addressed in the process of implementing OPRAS in the public service and develop practical measures to recover the areas of weakness. This would include setting enough budgets for the purpose of readdressing those elements highly ignored that have negative impact to the process of implementing OPRAS in KMC such as communicating the need for OPRAS and strongly inspiring employees to embrace OPAS application. It is further recommended that the government should reform the budgetary structure of the public service to allow specific itemized budget for the implementation of OPRAS rather than making it a subset to other 
items. This would facilitate and enable practical provision of OPRAS related training and motivation. Slackness of management in monitoring the implementation of OPRAS calls for a strong action by the government to address this challenge as it may hinder the implementation of OPRAS.

\section{Scope for future research}

OPRAS implementation in LGAs in Tanzania has so far attracted few studies. The scant literature on OPRAS implementation needs to be enriched by other studies to stimulate new scholarly work. The findings presented in this paper are significant contributions to the existing body of knowledge in performance management studies and staff performance in particular. Further research is needed to examine the usefulness of the OPRAS in the ministries, which will go a long way in enriching the available knowledge and providing policy recommendations. In this regard, other researchers may wish to conduct the same study and focus on central government's institution experience of OPRAS implementation.

\section{Research limitations}

Limitation in this study lies in the sample used in this study only focused on OPRAS implementation in KMC, so the conclusion drawn from this research cannot be generalized in other local government councils and central government Institutions in Tanzania. A further research on OPRAS implementation needs to be done in order to have more comprehensive results.

\section{References}

1. Sahoo C. K., Mishra S. Performance Management Benefits Organizations and their Employees. $\mathrm{Hu}$ man Resource Management International Digest, 2018, vol. 20, iss. 6, iss. 3-5.

2. Butt M.S.H., Khalid L. Effect of Performance Management on Employees Well-Being via Perceived Job Control. Macrothink Institute, Human Resource Research, 2018, vol. 2, no. 1.

3. Werner J.M. Human Resource Development/Talent Management ( $7^{\text {th }}$ ed.). Boston, Mass, Publisher Cengage Learning, 2017.

4. URT. Guideline on Open Performance Review and Appraisal System (OPRAS), President's Office - Public Service Management. Dar es Salaam, Government printer, 2013.

5. URT. Standing Orders for the Public Service. Dar es Salaam, Government printer, 2009.

6. Issa F. Policy and Methodologies for Evaluating Performance of the Public Service in Tanzania: A Paper Presented at an Expert Group Meeting on Human Resource Management Policy in the Public Sector in Africa-Held in Durban, South Africa, November, 2010.

7. Gorman C.A., Cunningham C.J.L., Bergman S.M., Meriac J.P. Time to change the bathwater: Correcting misconceptions about performance ratings. Industrial and Organizational Psychology, 2016, vol. 9 (2), iss. 314-322. https://doi.org/10.1017/iop.2016.18.

8. Waal A. A. Is Performance Management Applicable in Developing Countries? International Journal of Emerging Markets, 2007, vol. 2, no. 1, Netherlands.

9. Mothus B. Public Sector Reforms and Change Management in Botswana. VDM Verlag, 2009

10. Bana B. A. Performance Management in the Tanzania Public Service: A Paper Presented at the Conference on "Governance Excellence: Managing Human Potential" Held at Arusha International Conference Centre from 2-3 March, 2009, United Republic of Tanzania.

11. Oyomikun O I. Effectiveness of Performance Appraisal System and its Effect on Employee Motivation. Nile Journal of Business and Economics, 2017, vol. 5, iss. 15-39. http://dx.doi.org/10.20321/nilejbe. v3i5.88.

12. World Bank. Implementation Completion and Report Result for a Public Service Reform Project (IDA33000 IDA 3300A), 2008, p. 13. 
13. Laanyuni L. Implementation of Open Performance Review and Appraisal System in Tanzania Mainland: The Study of Selected Government Ministries. A Dissertation Submitted in Partial Fulfillment of A Degree of Master of Art in Public Administration at the University of Dar es Salaam, Dar es Salaam, 2011.

14. Muli R.K. The Impact of Performance Appraisal on Secondary School Teacher Professional Development in Kitui West District. (Unpublished Masters dissertation). Kenyatta University, Kenya, 2011.

15. Dmeglio P.C. Performance Measurement: How Gender Bias Corrupts Performance Reviews, and What to Do About It? Harvard Business Review, 2017. Available at: https://hbr.org/topic/performance-measurement (accessed: 14.08.2020).

16. Piderit K.S. Rethinking Resistance and Reorganizing Ambivalence: A Multi-dimensional View of Attitudes toward Organization Change. Academy of Management Review, 2000, vol. 25 (4), iss. 783-794.

17. United Republic of Tanzania (URT). Guideline on Open Performance Review and Appraisal System (OPRAS). Dar es Salaam, PO-PSM, 2011.

18. Down B., Chadbourne R., Hogan C. How are teachers managing performance management? Asia-Pacific Journal of Teacher Education, 2000, vol. 28, no. 3, iss. 213-223.

19. Armstrong M. A Handbook of Human Resource Management Practice. Cambridge, Cambridge University Press, 2006.

20. Kinondoni Municipality. Revenue Collection Reports. Dar es Salaam, 1999-2019.

Received: August 14, 2020 Accepted: December 28, 2020

Author's information:

Paul Mtasigazya - PhD; p.anton75@yahoo.com

\section{Управление работой персонала местного самоуправления в Танзании: опыт очных оценок производительности и системы поощрений в муниципальном совете Кинондони}

\section{П. Мтэзигэзья}

Академия Мвалиму Ньерере, кампус Каруме,

Танзания, Занзибар, а/я 307

For citation: Mtasigazya P. Local Government Staff Performance Management in Tanzania: Experience of Open Performance Review and Appraisal System (OPRAS) in Kinondoni Municipal Council. Vestnik of Saint Petersburg University. Asian and African Studies, 2021, vol. 13, issue 1, pp. 51-73. https://doi.org/10.21638/spbu13.2021.104

Рассматривается эффективность внедрения очных оценок производительности и системы поощрений (OPRAS) в работу сотрудников местных органов власти в муниципальном совете Кинондони (КМС) в Танзании. Для сбора данных использовались анкеты, глубинные интервью и документальный обзор. Размер выборки составлял 100 респондентов, а при анализе данных использовались методы контент-анализа и перекрестных таблиц. Основные результаты исследования показывают, что внедрение OPRAS было слабым из-за отсутствия информирования сотрудников о потребностях в OPRAS, проведения обучения, связанного с OPRAS, и недостаточного внимания к мотивации государственных служащих. Более того, местное самоуправление, особенно КМС, было очень слабо заинтересовано в том, чтобы его реализация была эффективной и устойчивой, о чем свидетельствует недостаток выделенных средств и установленных механизмов. Результаты показали отсутствие реальных усилий с точки зрения планов и стратегий, установленных для обеспечения эффективного и устойчивого внедрения OPRAS в KMC. Финансовые ограничения, вызванные отсутствием 
специального бюджета для внедрения OPRAS, слабость руководства в мониторинге внедрения OPRAS в KMC, а также недостаточные средства, выделяемые центральным правительством в КМС, являются основными факторами, сдерживающими эффективное внедрение OPRAS в KMC. Таким образом, можно сделать вывод о том, что правительство должно информировать государственных служащих о необходимости OPRAS и выделять средства для ее внедрения.

Ключевые слова: открытая оценка производительности, оценка результатов деятельности, эффективность работы персонала местного самоуправления, управление.

Контактная информация:

Мтэзигэзья Пол - PhD; p.anton75@yahoo.com 